\section{'CHECK BEFORE YOU TICK' CAMPAIGN LAUNCHED}

From 20 January 2020 new activity from NHS England and NHS Improvement, and NHS Business Services Authority (NHSBSA), encourages dental teams across England to support the NHS 'Check before you tick' campaign to help patients understand their eligibility for free or reduced cost NHS dental treatment.

The campaign is an extension of ongoing 'Check before you tick' prescriptions activity which launched for the first time in September 2018, helping patients to understand if they are entitled to receive free prescriptions and how to claim correctly to avoid unnecessary penalty charges.

The NHS makes checks on free and reduced cost dental claims each month; therefore, the campaign is important in helping to support dental teams to raise awareness of the need for people to check their entitlement using the NHS online eligibility checker. The eligibility checker can also let patients know about other means of support available to help them reduce the costs of dental treatment, such as the NHS Low Income Scheme.

A briefing, along with a toolkit of posters, counter cards and information booklets have been produced and sent to dental practices for use all year round to help remind patients to always 'check before you tick', using the NHS online eligibility checker. The materials and further digital resources are also available to download via the Campaign

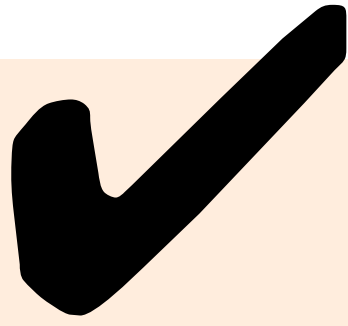

Resource Centre (https://campaignresources phe.gov.uk/resources/campaigns/100-checkbefore-you-tick-).

The campaign focuses primarily on patients making benefit-related claims who, according to audience research, can mistakenly assume they're automatically entitled to free dental treatment and may therefore need more help understanding their eligibility. There is also low awareness that the NHS makes checks on claims for free dental treatment and can issue a penalty charge of $£ 100$ in addition to the cost of treatment to those who have claimed incorrectly.

Dental teams are being encouraged to display the materials prominently, ensure staff are familiar with the eligibility criteria, and highlight to patients to check their entitlement before completing the patient declaration form.

Information about eligibility is also available to download from https://www. nhsbsa.nhs.uk/dont-get-caught-out-penaltycharges/check-you-tick in a number of alternative formats, including large print, easy read and BSL.

The online eligibility checker can be accessed at https://www.nhsbsa.nhs.uk/ dont-get-caught-out-penalty-charges/checkyou-tick.

\section{EEA mationals reminded to apply to the EU Settlement Scheme}

\begin{abstract}
All General Dental Council (GDC) registrants currently living in the UK on the basis of EU/EEA or Swiss citizenship need to apply to the Government's EU Settlement Scheme in order to retain their rights to stay in the UK after 30 June 2021. Individuals need to apply even if they have previously received a document certifying permanent residence.

The scheme is open for applications. It requires individuals to prove their identity and their length of presence in the UK. It is free to apply. Depending on the length of stay in the UK, individuals will be given settled status (if here for at least five years) or pre-settled status (if here for less than five years, with the option to change to settled status after five years). The BDA encourages all registrants with EU/EEA/Swiss nationality to apply in a timely way, and to encourage others, for example colleagues on career breaks or non-registrant team members, to do the same if applicable. Full information on the process is available at https://www.gov.uk/ settled-status-eu-citizens-families.
\end{abstract}

\title{
Erosive tooth wear
} symposiam planmed

A symposium entitled 'A Practical Approach to BEWE [the basic erosive wear examination] \& Management of Erosive Tooth Wear in Practice' will be held on Friday 17 April 2020 from 10:30 to 16:15 at Tower Lecture Theatre, Guy's Hospital, London.

Although tooth wear is the third most commonly observed oral condition, very few dental professionals are screening patients and recording erosive tooth wear (ETW) in patient records.

The symposium, developed for dentists, dental hygienists and dental therapists, is free to attend and will provide you with practical advice on management of ETW, from how to use the BEWE to useful hints on the effective restorative management of ETW in practice.

The event will be hosted by The Erosive Tooth Wear Foundation and KCL, and sponsored by GSK, and will bring together clinical experts in restorative dentistry and dentolegal experts to provide you with a practical 'nuts to bolts' overview of successful management in general practice. Speakers will include David Bartlett, Saoirse O’Toole, Shamir Mehta and Sachin Varma. CPD will also be provided.

For more information and to book your place, visit www.bewe.eventbrite.co.uk.

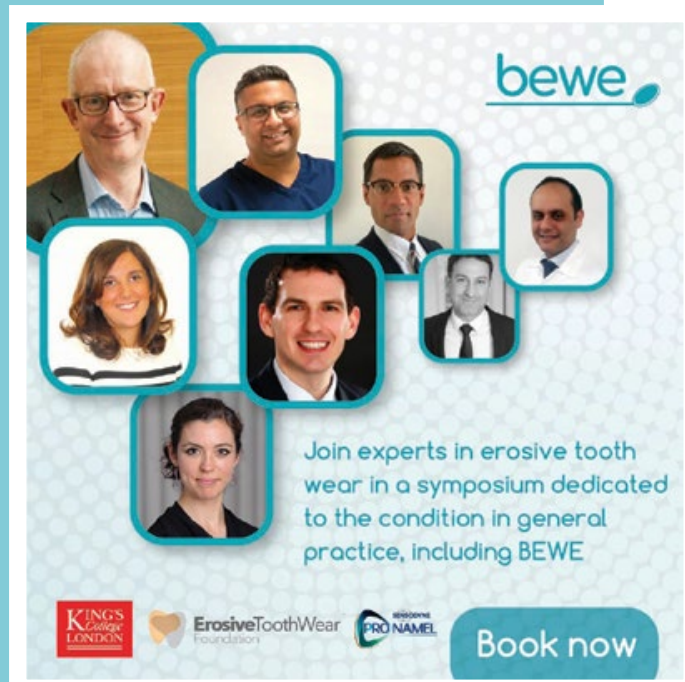

